\title{
Verification of Chiller Performance Promotion and Energy Saving
}

\author{
Yung-Chung Chang, Chao-Yuan Chen, Jyun-Ting Lu, Jin-Kwei Lee, \\ Tian-Shuen Jan, Ching-Liang Chen \\ National Taipei University of Technology, Taipei, Taiwan \\ Email: rasheed0701@hotmail.com
}

Received October 11, 2012; revised November 12, 2012; accepted November 23, 2012

\begin{abstract}
In this paper, the model of chiller power consumption is built by using the regression analysis. While taking the parameters from the operation data of chiller into consideration simultaneously, i.e. Partial Load Ratio (PLR), chilled water supply temperature and cooling water return temperature, the prediction results are quite accurate, and its accuracy reaches over $99 \%$ in short-term prediction when compared with the actual power consumption. This method can be used to validate the benefits of the chiller's energy saving method. The validation items include: the effect of water flow change on chiller's performance while multiple chillers operate in parallel; the power consumption analysis of centrifugal chiller operating with or without frequency conversion; as well as the discussion on whether the cleaning of condenser coil can improve the Coefficient of Performance (COP) of chiller or not. The case study results show that, while multiple chillers operate in parallel, the water flow change has limited effect on the performance of chiller. However, about 36\% electricity can be saved averagely when the chiller controls the frequency of electric power source at partial load, and the cleaning of condenser coil can increase the COP by $3.08 \%$.
\end{abstract}

Keywords: Chiller; PLR; COP; Regression Analysis

\section{Introduction}

Since the industrial revolution, the mankind has been relying on the energy. In recent years, with the vigorous development at home and abroad, the refining industry successfully expands the overseas oil market, and the import volume of industrial coal, electricity-generating natural gas and crude oil required by petrifaction are increased to a large degree, as a result, our energy supply has been growing obviously. As for the energy source, Taiwan's energy supply still mainly relies on import, which accounts for $98.2 \%$, and the self-supplied energy only occupies $1.8 \%$ [1]. Currently, more than $75 \%$ power generation in Taiwan is thermal power generation, of which most fuel source is fossil oil. Since the domestic economy grows stably, the energy consumption in Industry and commerce will also grows continuously in the future. According to the experts' statistics, with the present mining rate, we can carry on for another 40 years at most with oil and 200 years with coal. In the future, the energy shortage will definitely appear. To solve the energy shortage, we only have two measures, i.e. "source development" and "energy conservation". However, "source development" is very difficult, so we only have the solution of "energy conservation".

Located at subtropical regions, Taiwan is hot and wet in summer, which causes a big increase in the demand of air conditioners. Air conditioners include window-type, box type, indoor blower, central air conditioning system, etc. Those air conditioners consumes about $30 \%$ of electricity in summer [2], which even reaches about $40 \%$ at peak load [2]. In the central air conditioning system, the most important equipment is the chiller, which consumes more than $60 \%$ of the total power consumption in the system. Therefore, how to reduce the power consumption cost of air conditioners to improve the energy efficiency of chiller will be an important issue on reducing the power consumption and warming.

There are quite a lot of methods for energy conservation of air conditioning system. This study builds the power consumption model with linear regression to forecast the chiller's power consumption, so as to discuss the effect of water flow change on the chiller's performance and analyze the energy consumption of drive chiller in either variable frequency or invariable frequency mode. Finally, it validates the performance improvement before and after cleaning the condenser of chiller and the discussion of energy saving potential. 


\section{Case Discussion and Analysis}

\subsection{Effect of Water Flow Change on Chiller's Performance}

Based on the analysis on power consumption of some buildings, the power consumption of air conditioning systems in general commercial buildings occupies about $50 \%$ of the total consumption. The chiller, as the core of the central air conditioning system, consumes about $60 \%$ of the total power of the central air condition system. Therefore, if the power usage effectiveness of chiller can be improved, it will do a great help to promoting the central air conditioning system to save the energy and reduce the electricity consumption.

Generally, the air conditioning load required by the middle and large office buildings is big, so most of them adopt the design of multiple-chiller system. Moreover, the one-to-one allocation is adopted by the primary side water pump and chiller. In such mode, the water flow is fixed if the primary side water pump isn't collocated with the variable frequency control. This study is exemplified by one public organ, which is equipped with three centrifugal chillers, i.e. one 250-ton and two 400-ton chillers collocated with three $20 \mathrm{Hp}$ water pumps. If the 250 -ton chiller operates with one water pump, the water flow is $157 \mathrm{~m}^{3} / \mathrm{h}$; if it operates with three water pumps, the water flow is $116 \mathrm{~m}^{3} / \mathrm{h}$. Based on these parameters. This study is to discuss the chiller's performance change with the water flow change.

In this paper, the power consumption model of chiller collocated with a water pump is established through the regression analysis, and then the data measured by three water pumps are substituted into the model to analyze its performance change. The operation data measured on field are applied on the statistics software to get a regression analysis equation, by which the power consumption model of chiller is built as bellows [3]:

$$
k W=a_{0}+a_{1} X+a_{2} X^{2}+a_{3} Y+a_{4} Y^{2}+a_{5} X Y
$$

$a_{0}, a_{1}, a_{2}, a_{3}, a_{4}, a_{5}$ : regression coefficient

$X$ : Difference between cooling water return temperature and chilled water supply temperature;

$Y$ : Partial Load Ratio (PLR).

Table 1 shows the regression coefficient, in which the accuracy of chiller power consumption mode is so high $\left(R^{2}=0.99002\right)$ that it can be adopted. Table 2 shows the operation data range, in which the data range of chiller collocated with three water pumps are within that of chiller collocated with one water pump, i.e., the data can be substituted into the model to discuss the performance change.

The chiller occupies $60 \%$ of the power consumption of central air conditioning system, the water pump $11 \%$, the cooling water pump $13 \%$, the cooling tower $3 \%$, and the
Table 1. Regression coefficient of 250 -ton chiller operating with one water pump.

\begin{tabular}{lc}
\hline$a_{0}$ & 62.4307 \\
$a_{1}$ & -0.49409 \\
$a_{2}$ & 0.11425 \\
$a_{3}$ & -1.55136 \\
$a_{4}$ & 61.337 \\
$a_{5}$ & 0.5535 \\
$R^{2}$ & 0.99002 \\
\hline
\end{tabular}

Table 2. Data ranges of chiller collocated with one or three water pumps.

\begin{tabular}{ccc}
\hline & $\begin{array}{c}\text { One chiller water } \\
\text { pump }\end{array}$ & $\begin{array}{c}\text { Three chiller water } \\
\text { pumps }\end{array}$ \\
\hline TchwST & $7.8^{\circ} \mathrm{C}$ & $7.8^{\circ} \mathrm{C}$ \\
TcwRT & $16.66^{\circ} \mathrm{C}-31.28^{\circ} \mathrm{C}$ & $20.8^{\circ} \mathrm{C}-21.75^{\circ} \mathrm{C}$ \\
PLR & $0.285-0.947$ & $0.658-0.734$ \\
\hline
\end{tabular}

air handling unit and indoor blower 13\% [4], which indicate the chiller occupies the highest power consumption. For this reason, it deserves people's attention to improve the chiller's efficiency. Figure 1 shows the change of chiller's COP when collocated with one or three water pumps and it can be known that the effect of water flow change on the chiller's COP is slight, about $1 \%$.

\subsection{Variable-Frequency Chiller}

In general, there are three types of chillers, namely, centrifugal, screw and reciprocal chillers, in which the centrifugal or screw chillers are adopted by most air conditioning systems with large load. Design of general air conditioners calculates the peak load based on the climatic condition of the highest external air temperature and the indoor load to decide the capacity, so that the chiller mostly operates with partial load. However, the screw chiller can use the slide valve to realize continuous change. Therefore, it still keeps a good efficiency under partial load operation. The traditional centrifugal chiller adjusts the refrigerating ability through the guide vanes. Although the power consumption of compressor might drop when operating under partial load, the operation efficiency will decrease to a large degree, which causes a big waste of energy. The Variable Speed Drives (VSD) of the centrifugal chiller provides the chiller with a good efficiency by adjusting the rotation speed of motor and optimizing the location of guide vanes of compressor under various loads, especially when it operates under partial load. Therefore, this study analyzes the power conservation benefits of the inverter centrifugal chiller [5]. 


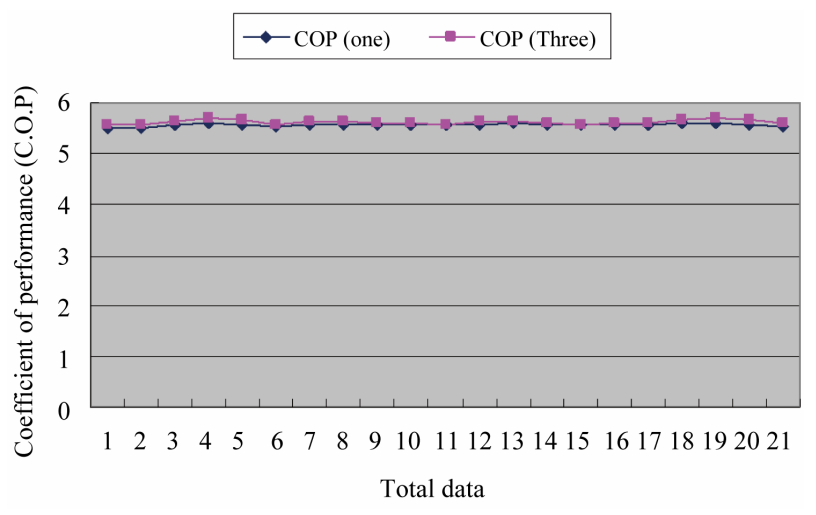

Figure 1. Effect of flow change on chiller's performance (one data/10 min).

This study adopts the actually measured data of the air conditioning system in one hypermarket, uses the linear regression to build the chiller power consumption model and discusses the power consumption analysis with variable frequency control and invariable frequency control. The data must be analyzed and compared within the same load range, and the measuring duration was from April 28 to May 6, 2008. We took records per minute of the chiller power, chilled water supply temperature, cooling water return temperature and water flow. Since the data was sampled instantly, we sorted the data by 10 minutes on average and then analyzed them by the quadratic regression to avoid error.

On April 29 and 30, the chiller was set as invariable frequency control mode, the chilled water supply temperature was $10^{\circ} \mathrm{C}$, the cooling water return temperature range was between $22.3^{\circ} \mathrm{C}-25^{\circ} \mathrm{C}$, and partial load ratio varied between $0.473-0.704$. In the rest days, the data were measured when the chiller operated in variable frequency mode, the chilled water supply temperature was $10^{\circ} \mathrm{C}$, the cooling water return temperature range was between $22.31^{\circ} \mathrm{C}-24.25^{\circ} \mathrm{C}$ and partial load ratio varied between $0.476-0.703$.

This study establishes the power consumption model of chiller in invariable frequency mode with the regression analysis, and then substitutes the data measured in variable frequency mode into the model to analyze its power saving potential. The operation data measured are applied to the statistics software to get a regression analysis equation, by which the power consumption model of chiller is built, and the regression coefficient is shown in Table 3.

In Table 4, the invariable frequency data are substituted into the built model, which gets the simulated total invariable frequency power of $12294.97 \mathrm{~kW}$, and the actually measured value is of $12294.95 \mathrm{~kW}$. Thus, the error ratio between the two is $0.00021 \%$, very close to zero. As for the single error, the maximum error is $1.19 \%$ and the minimum error is $0.0076 \%$, the average error is
Table 3. Regression coefficient in invariable frequency control mode.

\begin{tabular}{lc}
\hline$a_{0}$ & 171.85 \\
$a_{1}$ & 18.08 \\
$a_{2}$ & -2.096 \\
$a_{3}$ & -735.04 \\
$a_{4}$ & -90.57 \\
$a_{5}$ & 72.07 \\
$\mathrm{R}^{2}$ & 0.9958 \\
\hline
\end{tabular}

Table 4. Error ratio between total actual power and simulated power in invariable frequency control mode.

\begin{tabular}{cccc}
\hline $\begin{array}{c}\text { Total actual power in } \\
\text { invariable frequency } \\
(\mathrm{kW})\end{array}$ & $\begin{array}{c}\text { Total simulated in } \\
\text { invariable frequency } \\
\text { power }(\mathrm{kW})\end{array}$ & Error (\%) & $\begin{array}{c}\text { The average } \\
\text { error }(\%)\end{array}$ \\
\hline 12294.95 & 12294.97 & $0.00021 \%$ & $0.389 \%$ \\
\hline
\end{tabular}

$0.389 \%$. Therefore, it can be seen that the model has a quite high accuracy.

Figure 2 shows the comparison between actual invariable frequency control power and simulated one, in which the actual invariable frequency control power curve is very close to that of the simulated one. Thus, it can be proven that the model has a high accuracy.

The measured data of the chiller collocated with the inverter is classified per 10 minutes, 416 data in total. 193 data under the same load of the model are substituted into the model to validate the power saving effectiveness. Table 5 shows the power saved by the inverter chiller, the actual power of chiller in variable frequency control mode is $17187.4 \mathrm{~kW}$ and the simulated invariable frequency control power is $27059.6 \mathrm{~kW}$ under the same load. Thus, the variable frequency control can save about $36 \%$ of the power consumption.

It can be known from Figure 3, under the same conditions, the variable frequency control and invariable frequency control show great difference in the power consumption. In an energy conservation and carbon reduction era, the variable frequency control deserves to be promoted.

\subsection{Improvement of Chiller's Performance by Cleaning the Condenser Coil}

Ordinary air conditioning systems mainly have two big water circuits. The water circuit design is generally based on the flexible usage of actual requirements, which tends to the concept of primary and secondary side. Thus, the main function of water circuit is to bring the indoor heat back to the chilled plant to exchange with the cooling water circuit. While the main function of the cooling water circuit is to take away the indoor heat of water circuit and the heat produced by the compressor. When the 


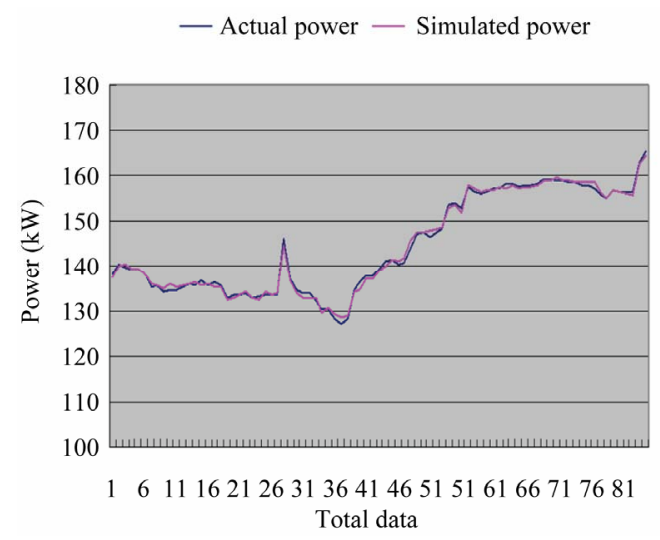

Figure 2. Comparison between actual invariable frequency control power and simulated invariable frequency control power.

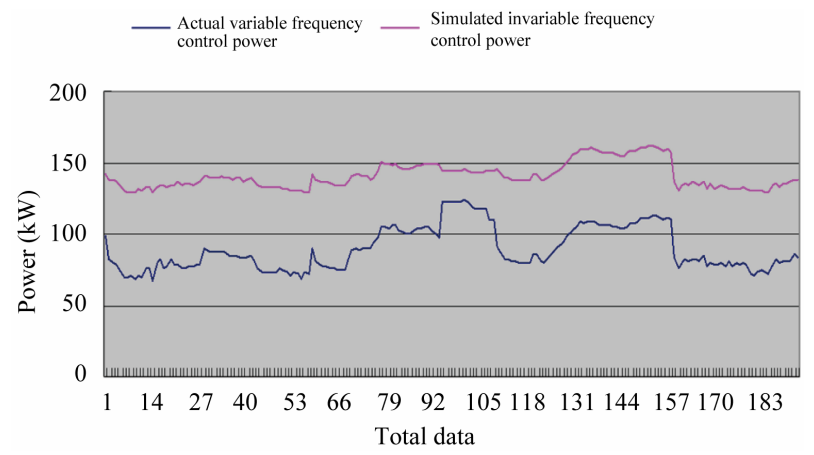

Figure 3. Comparison between actual variable frequency control power and simulated invariable frequency control power.

Table 5. Power conservation of actual variable frequency control power and simulated invariable frequency control power.

\begin{tabular}{cccc}
\hline $\begin{array}{c}\text { Actual variable } \\
\text { frequency control } \\
\text { power }(\mathrm{kW})\end{array}$ & $\begin{array}{c}\text { Simulated invariable } \\
\text { frequency control } \\
\text { power }(\mathrm{kW})\end{array}$ & $\begin{array}{c}\text { Power } \\
\text { saving }(\mathrm{kW})\end{array}$ & $\begin{array}{c}\text { Power saving } \\
\text { percent }(\%)\end{array}$ \\
\hline 17187.4 & 27059.6 & 9872.2 & $36.4 \%$ \\
\hline
\end{tabular}

heat exchange rate of condenser reduces, it will result in over-high voltage of the compressor, which will increase the power consumption of the compressor so as to reduce the entire COP of the system. Since the cooling water circuit is an open water system, the contact between water and air will cause water pollution in addition to the pollution source in the air. Generally, the cooling water is within the warm temperature range, which easily causes the generation of moss and scale, thus it is suggested cleaning and maintaining the condenser of air conditioning system every three months or half a year in order to keep a high heat exchange rate.

This study mainly focuses on the evaluation of system benefit improvement before and after cleaning the chiller's condenser of one hypermarket. Both the discussion of the method and the power consumption prediction are to validate the energy conservation, and it can act as a method to validate the evaluation on the technology of improving the performance of various system functions by the industry in the future [6].

This study adopts the actually measured data of the air conditioning system and uses the linear regression to build the chiller power consumption model so as to discuss the improvement of chiller's performance by cleaning the condenser coil. The data must be analyzed and compared within the same load range, and the measuring duration were from May 28 to June 24, 2008 (The condenser coil was cleaned on June 10). We took records per minute of the chiller power, chilled water supply temperature, cooling water return temperature and water flow, and then got the average data per hour. The data got from May 28 to June 9 were before cleaning, during which the chilled water supply temperature was $10.4^{\circ} \mathrm{C}$, the cooling water return temperature range was between $28.973^{\circ} \mathrm{C}-31.328^{\circ} \mathrm{C}$ and partial load ration varied between $0.3794-0.5927$. The data got from June 11 to June 24 were after cleaning, during which the chilled water supply temperature was $10.4^{\circ} \mathrm{C}$, the cooling water return temperature range was between $28.9^{\circ} \mathrm{C}-32.913^{\circ} \mathrm{C}$ and partial load ratio varied between $0.3494-0.629$.

This study establishes the power consumption model of chiller after cleaning the condenser coil, and then substitutes the data measured before cleaning into the model to analyze its performance improvement. The regression coefficient of chiller power consumption model is shown in Table 6.

Generally, when the evaluation coefficient $R^{2}$ reaches 0.95 , it indicates the method has quite high accuracy and reliability. It can be seen from Table 6 that, the regression coefficient has a high accuracy when its $R^{2}$ is above 0.95 .

In Table 7, the data are substituted into the model, which gets the simulated total power of $19066.732 \mathrm{~kW}$, and the actually measured one is of $19045.532 \mathrm{~kW}$. Thus the error ratio between the two is $0.111 \%$. The single error is $0.713 \%$. Therefore, it can be seen that the built model has a high accuracy.

Table 6. Regression coefficient after cleaning the condenser coil.

\begin{tabular}{lc}
\hline$a_{0}$ & 172.165 \\
\hline$a_{1}$ & -13.547 \\
$a_{2}$ & 0.4355 \\
$a_{3}$ & 116.648 \\
$a_{4}$ & -23.474 \\
$a_{5}$ & 0.498 \\
$R^{2}$ & 0.956 \\
\hline
\end{tabular}


Table 7. Error ratio between actual total power and simulated total power after cleaning.

\begin{tabular}{cccc}
\hline $\begin{array}{c}\text { After cleaning } \\
\text { actual total power } \\
(\mathrm{kW})\end{array}$ & $\begin{array}{c}\text { After cleaning } \\
\text { simulated total power } \\
(\mathrm{kW})\end{array}$ & $\begin{array}{c}\text { Error } \\
\text { ratio }(\%)\end{array}$ & $\begin{array}{c}\text { Single } \\
\text { error }(\%)\end{array}$ \\
\hline 19045.532 & 19066.732 & $0.111 \%$ & $0.713 \%$ \\
\hline
\end{tabular}
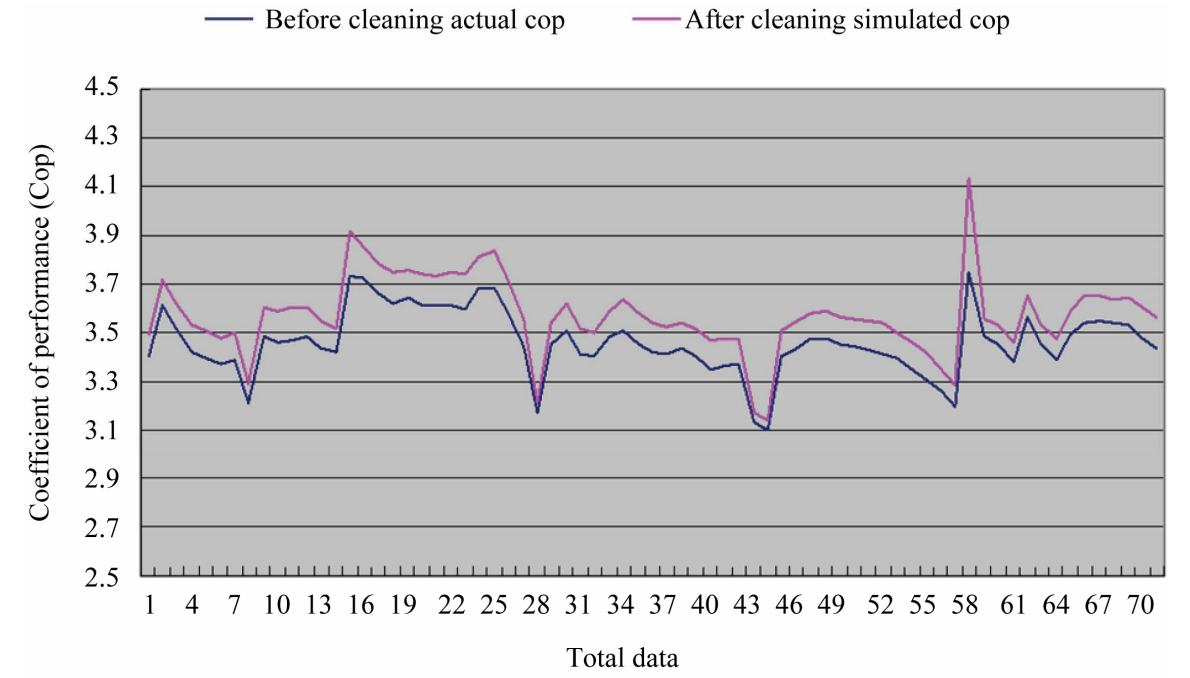

Figure 4. Comparison of COP before and after cleaning the condenser coil.

The measured data before cleaning the condenser coil were recorded per hour, 72 data in total. The data under the same load of the model are substituted into the model to validate the power saving effectiveness.

Table 8 shows the energy conservation calculation of cleaning the condenser coil. Before the improvement, the power consumption is $9385 \mathrm{~kW} \cdot \mathrm{h}$. After the improvement, the power consumption is $9093 \mathrm{~kW} \cdot \mathrm{h}$. Thus, the saving rate is $3.11 \%(292 \mathrm{~kW} \cdot \mathrm{h})$. Figure 4 shows the comparison of COP before and after cleaning the condenser coil.

\section{Conclusion}

In this study, the above three different cases are analyzed by the power conservation validation method, by which the following results are obtained: Partial Load Ratio (PLR), chilled water supply temperature and cooling water return temperature, the prediction results are quite accurate, and its accuracy reaches over $99 \%$ in short-term prediction when compared with the actual power consumption. We evaluate the power conservation of chiller with or without variable frequency control under the same load. It is shown from the study results that, the total power consumption of chiller with variable frequency control is $17187.4 \mathrm{~kW}$ during the test period, and that of the simulated invariable frequency control chiller is $27059.6 \mathrm{~kW}$, thus the power consumption of the chiller
Table 8. Energy conservation calculation of cleaning the condenser coil $(\mathbf{k W} \cdot \mathbf{h})$.

\begin{tabular}{cccc}
\hline $\begin{array}{l}\text { Power consumption mode Power consumption mode } \\
\text { before improvement (A) }\end{array}$ & $\begin{array}{c}\text { Saving } \\
\text { after improvement (B) }\end{array}$ & $\begin{array}{c}\text { Power } \\
\text { ravio }\end{array}$ \\
\hline 9385 & 9093 & $3.11 \%$ & $\begin{array}{c}292 \\
\mathrm{~kW} \cdot \mathrm{h}\end{array}$ \\
\hline
\end{tabular}

(Note: Power consumption before improvement is the cumulated amount of chiller after 72 hours of operation).

—After cleaning simulated cop 